\title{
Overview of Leachability of Heavy Metals using Solidification/Stabilization Method Incorporated with Agricultural Wastes
}

\author{
A. Benlamoudi ${ }^{1, a}$, A. Abdul Kadir ${ }^{2, b}$ and S. Ahmad Tajudin ${ }^{3, c}$ \\ ${ }^{1,2,3}$ Faculty of Civil and Environmental Engineering, University Tun Hussein Onn Malaysia, \\ 86400, Parit Raja, Johor, Malaysia. \\ aaliptbe.2009@yahoo.com, baeslina@uthm.edu.my, 'saifulaz@uthm.edu.my
}

Keywords: solidification/stabilization, leachability, heavy metals, agricultural wastes, adsorption.

\begin{abstract}
The solidification/stabilization (S/S) is one of the effective methods that are used for the heavy metals treatment. It was known that one of the main issues of this method is that the heavy metal is stayed inside the matrices, not destroyed nor adsorbed, which may cause serious problems for the environment once the matrices would be crashed. Agricultural wastes have shown a great capacity to the heavy metal adsorption from solid and liquid wastes. This paper reviews the incorporation of the agricultural wastes as heavy metals' adsorbents inside the matrices of the S/S method. In addition, changes in particle sizes, pre-treatment, temperature and other factors have also been discussed towards the heavy metal adsorption. Nevertheless, research regarding the incorporation of the agricultural wastes into the $\mathrm{S} / \mathrm{S}$ method is very minimal, and almost all the previous researches were only focusing comprehensively on the leaching characteristics of the method.
\end{abstract}

Introduction.Nowadays, Industrial production leaves enormous quantities of mineral wastes accompanied with toxic heavy metals like $\mathrm{Cd}, \mathrm{Hg}, \mathrm{As}$ and $\mathrm{Pb}$. These heavy metals are generally considered the most toxic to humans and animals, without any beneficial effects to them. Thus, they may cause acute diseases for the human beings such as dullness, restlessness, irritability, anemia, neurological effects and others [1]. Several methods have been conducted towards this matter to treat the heavy metals, among which the solidification/stabilization $(\mathrm{S} / \mathrm{S})$ is known as one of the effective methods through its low cost implementation and minimum energy consumption. Nevertheless, one of the main issues of this method is that the heavy metal is stayed inside the matrices, not destroyed nor adsorbed, which may cause serious problems for the environment once the matrices would be crashed. To address this problem, the incorporation of some agricultural wastes like rice husk, pineapple leaves, pine leaves, durian shell, coir pith, sugarcane bagasse was needed as heavy metals adsorbents. Different parameters like temperature, particle sizes, contact time, $\mathrm{pH}$ and others have shown different efficiencies for the heavy metal adsorption.In the other hand, some mechanical characteristics like the density and the compressive strength have shown different efficiencies towards the $\mathrm{S} / \mathrm{S}$ method.

Heavy metals adsorption by agricultural wastes.Different heavy metals could be discharged to the environment through various sources such as textile, plastics, mining, electroplating, metallurgical processing, batteries, tanneries, fertilizers, paper industries, pesticides, and refining ores [2]. Some of these heavy metals are very dangerous for the health and the environment. They may include arsenic $(\mathrm{As})$, cadmium $(\mathrm{Cd})$, chromium $(\mathrm{Cr})$, mercury $(\mathrm{Hg})$, lead $(\mathrm{Pb})$, thallium $(\mathrm{Tl})$ and others [8]. In order to avoid their toxicity, tremendous researches have been developed for the removal of heavy metals using low cost methods, among that the agricultural wastes incorporation has been highlighted in this part.

The landfilling of agricultural wastes may pollute the groundwater by infiltration and the environment through the greenhouse gas (GHG) emission in the atmosphere. As an alternative solution, some of these agricultural wastes like rice husk [4], pine leaves [5], durian shell [6], coir pith [7], oil palm shell [8] and watermelon shell [3] have shown an effective adsorption capability 
towards heavy metals. Sugarcane bagasse $[9,10,18]$ also has shown a high efficiency for the heavy metals adsorption.

Hegazy [4] has studied the adsorption of $\mathrm{Pb}$ contaminant by the rice husk $(\mathrm{RH})$. This research concluded that in a $\mathrm{pH}$ between 6 and 7 and a temperature of $25^{\circ} \mathrm{C}$, the total amount of metal adsorption by RH was $87.18 \%$ greater than it is with the fly ash, which was $76.1 \%$. In the same conditions of this study, the RH also showed a good adsorption for the $\mathrm{Cd}$, which was $67.9 \%$. In another study, Chong [8] concluded that the oil palm shell is an effective absorber for the $\mathrm{Pb}$, and the total adsorption of this heavy metal reached $3.39 \mathrm{mg} / \mathrm{g}$. Another research has showed an excellent capability of $\mathrm{Pb}$ adsorption by the modified areca waste, which obtained $95.5 \%$ of the metal [11].

Shafique et al. [5] have used the pine leaves to study the $\mathrm{As}(\mathrm{V})$ adsorption. As a result, they argued that an amount of $3.37 \mathrm{mg} / \mathrm{g}$ of this metal has been absorbed within only 35 minutes under $\mathrm{pH}$ of 4 . Better than this result, has been achieved by Jiménes et al. [12] using the iron modified pyrolyzed parsley, whereby the $\mathrm{As}(\mathrm{V})$ adsorption reached $18.17 \mathrm{mg} / \mathrm{g}$ in $6.5 \mathrm{pH}$.

The $\mathrm{Cr}(\mathrm{VI})$ adsorption was highlighted in other two researches that have been done by Suksabye and Thiravetyan [7] and Kurniawan et al. [8] using the coir pith and durian shell waste respectively. The results showed that the high adsorption was by incorporation of the modified coir pith by the Acrylic acid-grafted, which was $196 \mathrm{~g} / \mathrm{kg}$, followed by $165 \mathrm{~g} / \mathrm{kg}$ by using the coir pith alone, then, the durian shell, whereby the total amount of the $\mathrm{Cr}(\mathrm{VI})$ adsorption was $117 \mathrm{~g} / \mathrm{kg}$.

The SCB have been carried out by several researches. Homagai et al. [9] have used the charred xanthated sugarcane bagasse for different heavy metals, and found that it has a significant adsorption capacity which is more than that of various other biosorbents. The maximum loading capacities was found to be 225 for $\mathrm{Cd}(\mathrm{II}) \mathrm{mg} / \mathrm{g}, 318$ for $\mathrm{Pb}$ (II) $\mathrm{mg} / \mathrm{g}, 144$ for $\mathrm{Ni}$ (II) mg/g, 164 for $\mathrm{Zn}$ (II) $\mathrm{mg} / \mathrm{g}$, and 178 for $\mathrm{Cu}(\mathrm{II}) \mathrm{mg} / \mathrm{g}$, respectively. Another research by Sun [18], which showed that the modification of SCB could be much more effective than it is without modification. As an example, the adsorption of the $\mathrm{Cr}$ by the $\mathrm{SCB}$ alone was only $13.4 \mathrm{~g} / \mathrm{kg}$ much less than $\mathrm{Cd}, \mathrm{Cu}$ and $\mathrm{Pb}$ using the triethylene tetramine that was $313 \mathrm{mg} / \mathrm{g}, 133 \mathrm{mg} / \mathrm{g}$ and $133 \mathrm{mg} / \mathrm{g}$ respectively. Another conclusion that might be from this research is that the Succine anhydride plus the amine was the best modifier for the SCB to absorb the $\mathrm{Pb}$, which was $313 \mathrm{~g} / \mathrm{gk}$ compared to triethylene tetramine, sodium biocarbonate, ethelenediamine and succine anhydride alone that was $133 \mathrm{mg} / \mathrm{g}, 196 \mathrm{mg} / \mathrm{g}$, $164 \mathrm{mg} / \mathrm{g}$ and $189 \mathrm{~g} / \mathrm{kg}$. An excellent result of the $\mathrm{Pb}$ adsorption was achieved by Martin-lara et al. [10], who argued that at $25^{\circ} \mathrm{C}$ and with a fixed $\mathrm{pH}$ of 5 , the total adsorption of $\mathrm{Pb}$ by $\mathrm{SCB}$ with or without its treatment by $\mathrm{H}_{2} \mathrm{SO}_{4}$ may reach $100 \%$ at low concentration of the $\mathrm{Pb}$ ions $(10 \mathrm{mg} / \mathrm{l})$.

Some factors may affect the adsorption capacity of heavy metals by $\mathrm{SCB}$, such $\mathrm{pH}$, temperature, initial heavy metal concentration, biosorbent, dose, biosorbent size, ionic strength, co-ions and others. Martin-lara et al. [10] have studied the initial $\mathrm{Pb}$ concentration and concluded that, as $\mathrm{Pb}$ concentrations increased, the removal efficiency decreased from $100 \%$ to $37 \%$ for SCB and $100 \%$ to $41 \%$ for $\mathrm{H}_{2} \mathrm{SO}_{4}-\mathrm{SCB}$. Thus, increasing the initial lead concentrations in the solutions decreased the removal efficiency.

Taha et al. [13] investigated the role of $\mathrm{pH}$ in the adsorption $\mathrm{Pb}(\mathrm{II}), \mathrm{Cd}(\mathrm{II})$ and $\mathrm{Zn}$ (II) ions using potato peels. They reported that the removal efficiency increased with increasing $\mathrm{pH}$ values from 2 to 6. Another research have been carried out by Giri et al. [14], who have studied the effect of $\mathrm{pH}$ on the removal of $\mathrm{Cr}$ (VI) using Eichhornia crassipesroot activated carbon. They argued that the maximum adsorption of the $\mathrm{Cr}(\mathrm{VI})$ increased from $50.23 \%$ to $92.24 \%$ with the increase of $\mathrm{pH}$ from 1.5 to 4.5 .

In terms of temperature, Kumar et al. [15] found that the biosorption of $\mathrm{Cd}(\mathrm{II})$ by cashew nut shell decreased from $80.13 \%$ to $74.32 \%$ with the rise in temperature from $30^{\circ} \mathrm{C}$ to $60^{\circ} \mathrm{C}$. El-Sayed et al. [16] noticed that adsorption percentage of $\mathrm{Zn}$ (II) decreased from $52 \%$ to $28 \%$, from $34 \%$ to $16 \%$ in case of $\mathrm{Cd}(\mathrm{II})$ and from $39 \%$ to $13 \%$ for $\mathrm{Mn}(\mathrm{II})$, as the temperature increased from $25^{\circ} \mathrm{C}$ to $55^{\circ} \mathrm{C}$.

Banerjee et al. [3] reported that the decreasing of particles size of watermelon shell may increase the removal efficiency of $\mathrm{Cu}(\mathrm{II})$. Kelly-Vargas et al. [17] also found that material with $1 \mathrm{~mm}$ of particle size showed higher retention capability (up to $12 \%$ ) than the material with $2 \mathrm{~mm}$ of particle 
size. In the same way, Kannan and Veemaraj [19] concluded that the decreasing of particle size of Jackfruit seed carbon, from 250 to $90 \mu \mathrm{m}$ increase the removal of $\mathrm{Cd}(\mathrm{II})$ from $10.07 \%$ to $53.16 \%$.

According to Chun and Abd Kadir [20], the contact time has its effect on the metal adsorption. They argued that the percentage of $\mathrm{Zn}$ removal was increased due to the contact time of 0.5 hours to 1.5 hours which were $60.40 \%$ ( 0.5 hour), $80.20 \%$ ( 1 hour $)$ and $86.14 \%$ ( 1.5 hours). In the same way, Alfa et al. [21] studied the remove of $\mathrm{Pb}(\mathrm{II})$ and $\mathrm{Cu}$ (II) ions from aqueous solutions by using frond and leaf samples prepared from dump palm tree. The time intervals chosen for this experiment were $30,60,90,120$ or 150 minutes. They observed an increase in the percentage adsorption of metal ions with time until 90-minutes contact time. The results showed that the $\mathrm{Cu}$ (II) ions had the highest percent removal of $64 \%$ and $60 \%$ for frond and leaves respectively, and $\mathrm{Pb}$ (II) with the percentage removal of $56 \%$ and $44 \%$ for frond and leaves respectively. Thus, they concluded that the best condition for sorption of $\mathrm{Pb}$ (II) and $\mathrm{Cu}$ (II) is 90 -minutes contact time for both substrates.

Overview of the $\mathbf{s} / \mathbf{s}$ method incorporated with agricultural wastes. Only few researches have been conducted towards this matter. In fact, the focus of the $\mathrm{S} / \mathrm{S}$ method in the recent years is more towards the incorporation of mineral additives such as lime and pozzolans, and generally only fly ash and bottom ash are incorporated as organic additives. The sugarcane bagasse have been used as an additive by Janusa et al. [22]. In this research, concentrations of $10 \%$ and $15 \%$ of $\mathrm{Pb}$ by weight to cement loading have been used and cured for 7,14 , and 28 days at $24^{\circ} \mathrm{C}$. The results showed that the samples containing SCB typically resulted in TCLP (modified) extract concentrations of approximately $0.5 \mathrm{mg} / \mathrm{l}$ of lead for all samples. In the other hand, samples containing no bagasse extract concentrations of $\mathrm{Pb}$ of approximately $5 \mathrm{mg} / 1$ and $45 \mathrm{mg} / 1$ for $10 \%$ and $15 \%$ of $\mathrm{Pb}$ nitrate samples respectively. Thus, the utilization of SCB as an additive to cement effectively improved the $\mathrm{S} / \mathrm{S}$ of $\mathrm{Pb}$.

Recently, another research have been carried out by Mardiha [23] in UTHM campus. This study argued the possibility to incorporate the natural rice husk $(\mathrm{RH})$ at an optimum percentage of $5 \%$, in fine particles $(<425 \mu \mathrm{m})$ with $5 \%$ of cement to stabilize the clay soil. Although this percentage may affect the solidification properties of the specimens, but they still fit the standards. This research could be used only for soil stabilization, thus, it have to be proved for the heavy metals adsorption.

Few studies also have been conducted for the heavy metals adsorption from contaminated soil using agricultural wastes ashes.

However, Yin et al [24] have proved that the replacement of OPC with RHA for Cement-dried soil $(\mathrm{C} / \mathrm{Sd})$ ratio of 1 reduced the leachability of lead from 0.66 to $0.08 \mathrm{mg} / \mathrm{L}$ in the acetic acid. This result indicated that the usage of ordinary Portland cement (OPC) with rice husk ash (RHA) as an overall binder system for the $\mathrm{S} / \mathrm{S}$ of lead-contaminated soils is more favorable in reducing the leachability of lead from the treated samples than a binder system with standalone OPC. This research indicated also that, even though partial replacement of OPC with RHA in the binder system reduced the UCS of solidified samples, it was still high enough to exceed the mortar limit of $20 \mathrm{~N} / \mathrm{mm} 2$, which was more than sufficient to be reused as construction materials.

Another research have been carried out by Jain [25] who studied the effect of Cr (VI) (1000-3000 $\mathrm{mg} / \mathrm{l}$ ) on solidification and hydration behavior of Ordinary Portland cement (OPC) and rice husk ash (RHA) blended $(10 \%, 20 \%$, and 30\%). He concluded that during TCLP tests, blended samples with $20 \%$ of RHA (R20) show high retention capacity for Cr (VI) as compared to blended samples without ash (R0) in acidic $\mathrm{pH}=3$. He noticed that although the decrease the $20 \%$ incorporation of RHA to the binder exhibited a decrease in the UCS value, but it was greater than the EPA compressive strength $(0.34 \mathrm{MPa})$ requirement for $\mathrm{S} / \mathrm{S}$ treatment of hazardous wastes. These results showed that rice husk ash-blended cement is an adequate binders to confine the high concentration of hazardous $\mathrm{Cr}$ (VI) for reduction of negative impact on land and ground water quality.

In the same way, Asavapisit \& Ruengrit [26] have studied the role of RHA-blended cement in stabilizing metal-containing wastes. They argued that concentration of heavy metals in the TCLP leachates was very low when cement was blended with $10 \%$ of RHA. They concluded also that The 
plating sludge could be loaded at 30\% to the cement blended with $10 \%$ RHA and resulted in either the minimum acceptable 28-day strength or the maximum level of metal leaching that meets the minimum requirement for landfilling.

Conclusion.This literature review showed that many attempts have been carried out in order to minimize the heavy metals from solid and liquid wastes using solidification method and the adsorption as well. The adsorption using different agricultural wastes is concluded as an effective low cost method for the elimination of heavy metal, which may reach until $100 \%$. This method is influenced by some factors such as $\mathrm{pH}$, temperature, initial heavy metal concentration, biosorbent type and dose, particle sizes, and others, thus, the maximum adsorption of the heavy metals could be changed.

The solidification/stabilization method also, has shown a good capacity in the encapsulation of the heavy metals inside the matrices. The incorporation of the agricultural wastes may be one of best ways to adsorb the heavy metals within the matrices, thus, the elimination of danger. The percentage of these agricultural wastes, their particles' sizes and their pretreatment affect the mechanical properties of the matrices such as the density, the strength, the water absorption and others to be stored in the landfill.

However, research regarding the incorporation of the agricultural wastes into the S/S method is very minimal, and almost all the previous researches were only focusing comprehensively on the leaching characteristics of the method. Hence, it is recommended to conduct such researches in the future studies.

\section{References}

[1] Health Protection Agency (EPA) (2012). Lead Toxicological overview. United Kingdom.

[2] Q. Manzoor, R. Nadeem, M. Iqbal, R. Saeed, T. M. Ansari,Organic acids pretreatment effect on Rosa bourboniaphyto-biomass for removal of $\mathrm{Pb}(\mathrm{II})$ and $\mathrm{Cu}(\mathrm{II})$ from aqueous media, Bioresource Technology. 132 (2013) 446-452.

[3] K. Banerjee, S.T. Ramesh, R. Gandhimathi, P.V. Nidheesh,K.S. Bharathi, A novel agricultural waste adsorbent, watermelon shell for the removal of copper from aqueous solutions, Iranica Journal of Energy \& Environment. 3 (2012) 143-156.

[4] H. A. Hegazy, Removal of heavy metals from wastewater using agricultural and industrial wastes as adsorbents, HBRC Journal, 9 (2013) 276-282.

[5]U. Shafique, A. Ijaz, M. Salman, W. u. Zaman, N. Jamil, R. Rehman, A. Javaid, Removal of arsenic from water using pine leaves, Journal of the Taiwan Institute of Chemical Engineers.43 (2012) 256-263.

[6] A. Kurniawana, V. O. A. Sisnandya, K. Trilestaria, J. Sunarsob, N. Indraswatia, S. Ismadjia, Performance of durian shell waste as high capacity biosorbent for $\mathrm{Cr}$ (VI) removal from synthetic wastewater, Ecological Engineering.37 (2011) 940-947.

[7] P. Suksabye, P. Thiravetyan, Cr(VI) adsorption from electroplating plating wastewater by chemically modified coir pith, Journal of Environmental Management. 102 (2012) 1-8.

[8] H.L.H. Chong, P.S. Chiaa, M.N. Ahmad, The adsorption of heavy metal by Bornean oil palm shell and its potential application as constructed wetland media, Bioresource Technology. 130 (2013) 181-186.

[9] P. L. Homagaia, K. N. Ghimirea, K. Inoueb,Preparation and Characterization of Charred Xanthated Sugarcane Bagasse for the Separation of Heavy Metals From Aqueous Solutions,Separation Science and Technology. 46 (2010) 330-339. 
[10] M. Á. Martín-Lara, I. L. R. Rico, I. C. A. Vicente,G. B. García and M. C. Hoces, Modification of the sorptive characteristics of sugarcane bagasse for removing lead from aqueous solutions, Desalination. 256 (2010) 58-63.

[11]X. Li, W. Zheng, D. Wang, Y. Qi, J. Cao, X. Yue, T. Chan, G. Zeng, Removal of Pb (II) from aqueous solutions by adsorption onto modified areca waste: Kinetic and thermodynamic studies, Desalination.258 (2010) 148-153.

[12]M.J. Jiménez-Cedilloa, M.T. Olguína, C. Fall, A. Colin-Cruz, As(III) and As(V) sorption on iron-modified non-pyrolyzed and pyrolyzed biomass from Petroselinumcrispum (parsley), Journal of Environmental Management.117 (2013) 242-252.

[13] G.M.Taha, A.E.Arifien, S.El-Nahas, Removal efficiency of potato peels as a new biosorbent material for uptake of $\mathrm{Pb}(\mathrm{II}), \mathrm{Cd}(\mathrm{II})$ and $\mathrm{Zn}$ (II) from the aqueous solutions, Journal of Solid Waste Technology Management. 37 (2011) 128-140.

[14]A.K.Giri, R. Patel, S. Mandal, Removal of $\mathrm{Cr}(\mathrm{VI})$ from aqueous solution by Eichhorniacrassipes root biomass-derived activated carbon, Chemical Engineering Journal.185-186 (2012) 71-81.

[15]P.S. Kumar, S. Ramalingam, V. Sathyaselvabala, S.D. Kirupha, A.Murugesan, S.Sivanesan, Removal of Cd(II) from aqueous solution by agriculturalwaste cashew nut shell, Korean Journal of Chemical Engineering. 29(2012) 756-768.

[16] G. O. El-Sayed, H. A. Dessouki and S. S. Ibrahiem, Removal of Zn(ii), Cd(ii) and Mn(ii) from aqueous solutions by adsorption on maize stalks, The Malaysian Journal of Analytical Sciences. 15 (2011) 8-21.

[17] K. Kelly-Vargas, M. Cerro-Lopez, S. Reyna-Tellez, E. R. Bandala, J. L. Sanchez-Salas, Biosorption of heavy metals in polluted water, using different waste fruit cortex, Physics and Chemistry of the Earth, Parts A/B/C. 37-39 (2012) 26-29.

[18] R. Sun, Cereal straw as a resource for biomaterials and sustainable biofuels, third ed., Amsterdam; The Netherlands, 2012.

[19] N. Kannan, T. Veemaraj, Batch adsorption dynamics and equilibrium studies for the removal of $\mathrm{Cd}(\mathrm{II})$ ions from aqueous solution using jack fruit seed and commercial activated carbons - a comparative study, Electronic Journal of Environment, Agriculture and Food Chemistry. 9(2010) $327-336$.

[20] O. H. Chun \& A. Abdul Kadir, Application of Coffee Waste in Removing Zinc of River Water, International Journal of Zero Waste Generation. 1 (2013) 17-22.

[21] Y. M. Alfa, H. Hassan, U. I. Nda-Umar, Agricultural waste materials as potential adsorbent for removal of heavy metals from aqueous solutions, International Journal of Chemistry Research, 2 (2012) 48-54.

[22] M. A. Janusa, C. A. Champagne, J. C. Fanguy, G. E. Heard, P. L. Laine and A. A. Landry, Solidification/stabilization of lead with the aid of agasse as an additive to Portland cement, Microchemical Journal. 65 (2000) 255-259.

[23]M. Mokhtar, Mechanical properties of soft clay stabilized with cement-Rice husks (RH), 2011, unpublished.

[24] C.Y. Yin, H. Mahmud and M.G. Shaaban, Stabilization/solidification of lead-contaminated soil using cement and rice husk ash, Journal of Hazardous Materials.137 (2006), 758-1764.

[25]N. Jain, Solidification and Leachability of $\mathrm{Cr}$ (VI) in Rice Husk Ash-Blended Cement, International Scholarly Research Network.201 (2011)1-6.

[26] S. Asavapisit\& N. Ruengrit, The role of RHA-blended cement in stabilizing metal-containing wastes, Cement \& Concrete Composites.27 (2005) 782-787. 